\title{
87. Jahrestagung der Deutsche Gesellschaft für Kardiologie - Herz- und Kreislaufforschung e.V
}

07. - 10. April 2021

๑) Springer-Verlag GmbH Germany, part of Springer Nature 2021

Tagungsthema

Grenzen überwinden und neue Welten entdecken

Overcome boundaries and discover new worlds

Tagungspräsidentin

Prof. Dr. Denise Hilfiker-Kleiner, Marburg

\begin{abstract}
s
Dieser Link führt Sie zur Abstracts-Datenbank, in der Sie per Schlagwortsuche online nach Dokumenten suchen können.

This link leads you to the searchable online abstract data base. https://dgk.org/kongress_programme/jt2021/abstracts/
\end{abstract}

